\title{
'I am not being sponsored to say this': a teen youtuber and her audience negotiate branded content
}

\author{
Ana Jorge*, Lidia Marôpo**, Thays Nunes*** \\ *Universidade Católica Portuguesa, CECC, Portugal \\ **Instituto Politécnico de Setúbal, CICS.NOVA, Portugal \\ ***Independent researcher
}

\begin{abstract}
The field of microcelebrity is increasingly monetised, professionalised, and institutionalised, with the growing recognition of content creators as social media influencers. This article looks at the integration of branded content within youth digital culture, where participatory possibilities for self-expression are more and more entwined with consumer culture. It seeks to discuss how digital producers understand brand culture and how audiences negotiate the meanings of the commercialism inserted in their content. We look at the case of SofiaBBeauty, a successful young Portuguese youtuber, who has been vlogging since she was 12 . The article analyses her association with brands in 12 videos in 2017 (vlog, haul, giveaway, Q\&A, first impression, etc.), and the comments by the users showing acceptance and appraisal of, negotiation, or criticism towards, the brand and/or the youtuber. We explore the way Sofia connects her self-presentation with products/brands to appear close to her young audiences, and brands her persona as she is growing up to adulthood; how she presents her commercial recommendations as genuine and pregnant with affect, and whether the audience accepts it or not; as well as how she positions herself in the global YouTube community of practice, where connection with brands aggrandizes her persona in the eyes of the audience. Sofia's videos create a post-feminist subject where consumption is articulated with independence, capability, and empowerment (Banet-Weiser, 2011), while engaging her audiences in a commodification process (Berryman \& Kavka, 2017).
\end{abstract}

Keywords: Youth; audiences; commercialism; social media; microcelebrity; commodification

\section{Introduction}

In the late 1990s and early 2000s, the online media allowed for 'do-it-yourself' (DIY) celebrities (Evans \& Hesmondhalgh, 2005), "bypassing the gatekeeper role of media and entertainment industries (Turner, 2014)" (Hou, 2018, p.2), as well as "one-hit", instantaneous, sometimes unwanted fame such as "Star Wars Kid' on YouTube (Marwick \& boyd, 2011) or 'Leave Britney Alone' - an accidental, evanescent fame, in the continuation of a 'demotic' turn from television in the late 1990s with reality television (Turner, 2010). With the rise of web 2.0, new personalities came into the public eye, without the intermediation of traditional media (Jerslev, 2016). First through forums and blogs, then through video and social media platforms, ordinary users produced content to engage audiences and compete for their attention through affectivity (Burgess \& Green, 2009; Senft, 2013).

As advertising and marketing adapted - and migrated - into digital media, to follow the fragmentation of audiences into web 2.0, forms of personal engagement became more and more the locus for commercial 
communication. In a few years, 'digital influencer' has become a job designation used in marketing and academia alike, and known by the public at large (Hearn \& Schoenhoff, 2016). In this process of professionalization and industrialisation, youtubers, bloggers or instagrammers engage and are engaged in self-commodification as well as in commodification of their audiences. This article looks at the interactions between content creators and audiences around commercial aspects - crucial in the 'influencer' model through a non-Anglo-Saxon case of a teen youtuber, to discuss the partial colonisation of amateur youth culture by commercialism.

\section{YouTube as Platform}

A lot has changed since YouTube was created in 2005 by three PayPal employees as a 'digital video repository' based on user-generated content (UGC). The following year, the user-friendly and ad-free site, comparable at the time to other video start-ups, was bought by Google for $\$ 1.65$ billion and rapidly became a major venue for the distribution of popular culture by the entertainment industry, while establishing itself as an inescapable player of this profitable industry (Burgess \& Green, 2009; Holland, 2017). YouTube is today a huge global cultural phenomenon: the second most visited site in the world, after Google (Alexa, $\mathrm{n} / \mathrm{d}$ ) with more than a billion users, one third of the online population. Despite news that the platform has had $\$ 4$ billion in revenue in 2014 (Winkler, 2015), CEO Susan Wojcicki said in 2016 that YouTube is still in investment mode and doesn't generate profits (Rao, 2016).

YouTube's popularity results from the combination of visualisation of videos and social interaction (Lange, 2008; Khan, 2017). For the first part, YouTube has invested in audio-visual features: it is now organised according to channel, rather than video, and the user is increasingly treated as a viewer and a consumer (Van Dijck, 2013). For the second, over time the platform invested in social media affordances: users can create an individual profile (channel), subscribe to other channels, receive notifications, 'like', 'dislike' or share videos, comment and create playlists. At the same time, the combination of the app with the proliferation of mobile and smart media led to a more personalised experienced, where data is gathered and used continuously by the platform to adapt recommendations.

Its tagline 'Broadcast Yourself' has been retired in favour of a heavily commercialised ad-friendly environment. YouTube mainly generates income through in-site advertising, paying a percentage to partners' channels (Statista, n/d; Cunningham \& Craig, 2017). In 2018, channels reaching 4.000 watch hours in the previous 12 months and 1.000 subscribers could apply to join The YouTube Partner Program (YouTube, $\mathrm{n} / \mathrm{d}$ ). This monetisation is intensively promoted by YouTube, which instils a DIY culture encouraging its users with the hope of being 'credible content creators' (Bakioglu, 2018) and "rewarding them economically for promoting themselves" (Raun, 2018, p.100). The platform offers support to navigate and thrive as creator: the channel YouTube Creators offers guidelines and tutorials on how to be an 'authentic' and 'creative' content producer and on how to make one's channel grow; while nine highly 
equipped studios in main cities across the world - dubbed YouTube Spaces - are available to registered content producers by appointment and also act as places for events and workshops.

This development of YouTube promoted self-commodification as an integrated part of self-representation on the platform and, at the same time, changed YouTube as a culture (Raun, 2018). Some of the most popular YouTube channels are not owned by brands but by online personalities. The top 3\% most watched channels in 2016 within their first year of existence (which attract $85 \%$ of views) present a mix of UGC and professionally produced videos (Bärtl, 2018). YouTube thus became an ideal space to craft the self-as-brand: from gaming to fashion and beauty tips, from unboxing toys to comedy, many professional-amateur content creators invest time and energy to attract attention and engage in the self-commodification of their online identity, borrowing strategies and logic from commercial brand culture (Banet-Weiser, 2011). Followers give attention to the producers' content, being quickly transformed into value as number of subscribers, views and 'likes', for the benefit of the content creators and also of the YouTube platform. This so called 'attention economy' (Senft in Berryman \& Kavka, 2018) transformed two million (out of one billion) users into 'partners' (Cunningham \& Craig, 2017). "More and more home-grown YouTube stars are turning into professional content creators" (Hou, 2018, p.2), with scheduled or regular content production and high technical quality. YouTube presses towards professionalization, as trending videos favour creators that are more regular. On YouTube, "stars matter (...): those that rise, hold, and grow large follower bases are important players in ensuring revenue generation from UGC" (Postigo, 2016, p.345).

YouTube is thus a "paradigmatic example of a hybrid commercial environment where UGC production is efficiently tied to forms of monetization" (Arthus, Drakopoulou and Gandini, 2018, p.7). This 'hybrid culturalcommercial space' (Lobato, ibidem), alongside other digital spaces, is gaining academic and social attention over its power and social influence. Namely, there are concerns regarding the opacity of Internet companies (especially YouTube/Google) and their relationship with their users, who are at the same time producers and consumers of content, the so-called prosumers. "What has transformed social media sites like YouTube, Facebook, and Twitter into multimillion dollar companies is precisely this form of unrecognised labour that is based on unwaged, voluntary given work" (Bakioglu, 2018, p.191). Stehling et al. (2018) attest that the processes of co-option of audience content by powerful institutions such as Google is constantly oscillating between the empowerment and exploitation of audiences, in a permanent tension between participatory culture and media producers. UGC involves recognition, pleasure and also financial compensation for youtubers, while being commodified according to the 'mystery' of YouTube's algorithm that determines viewing suggestions and recommendations (Cunningham et al. apud Arthurs et al., 2018, p.7). On the list of academic and public concerns over YouTube, including issues such as 'fake news' or 'hate speech' (Arthurs et al., 2018), one may include the relationship with children, especially regarding exposure to harmful content, over promotion of consumer culture and child labour as digital content producers.

For youth culture, amidst commodification, social media - notably YouTube - create a powerful public venue for self-expression (McRoberts, Bonsignore, Peyton \& Yarosh, 2016), bringing potential benefits such as public visibility of girlhood cultures, peer recognition and opportunities to improve their self-presentation and technical skills (Marôpo, Sampaio \& Pereira, 2018). For Lange (2014), commercialisation is not 
incompatible with family/friend affection or learning process among content creators; the author stresses that regular young youtubers show through words or actions their beliefs, values, or practices while forming collectively generated 'communities of practices', which include routines, conventions and shared stories. In terms of gender and sexuality, social media has been allowing for the affirmation of alternative identities (cfr. Lovelock, 2016 on 'coming out' videos) and opened up space for girls as digital producers (BanetWeiser, 2011). However, they pose constraints to youth identities, not least because of their commitment to commercialism (idem; Berryman \& Kavka, 2017; Genz, 2015; Tomaz, 2017; Raun, 2018). In this sense, feminine identity is framed by a cultural post-feminism context, combining individualistic agency of digital self-entrepreneurship, and empowerment, overlapped into "pre-scripts of femininity, beauty and sexiness" in a "perplexing double binds of discipline and choice" (Genz, 2015, pp.545-546). The entrepreneurs of the self (Rose, 1999) rely on strategies of authenticity and intimacy in which emotion and affection are crucial elements in the construction, marketing and consumption of feminine subjectivity (Genz, 2015; Berryman \& Kavka, 2017).

\section{From self-expression to digital influence}

In recent years, the role of ordinary content creators on YouTube is superseding that of the content itself. Together with personalities arising as ordinary, yet especially productive users from social media, youtubers came to the public (however niche) eye. These online personalities deploy microcelebrity (Senft, 2013; Marwick and boyd, 2010), a communicative practice which can be defined as a self-presentation technique in which social media users behave as a public persona in the face of others, using "strategic intimacy to appeal to followers, and regard their audience as fans" (Marwick, 2015, p.333). Social media emulate traditional celebrity presentation in an environment accessible to ordinary users that allows for greater proximity, authenticity and immediacy (Marwick \& boyd, 2010).

The terms used were also initially borrowed from previous marketing practices, such as 'digital ambassador' for someone from the digital realm of UGC associated with a brand in more than one form of content. Over the last years, 'ambassador' has largely been replaced - in the industry as well as academia (Abidin \& Ots, 2016) - by the term '(social media) influencer' to speak of association of celebrities in social media with brands, commercial and non-commercial (Khamis et al., 2017; Hearn \& Schoenhoff, 2016). Abidin (2015) defines influencers as:

"everyday ordinary Internet users, who accumulate a relatively large following on blogs and social media through the textual and visual narration of their personal lives and lifestyles engage with their following in digital and physical spaces, and monetize their following by integrating 'advertorials' into their blog or social media posts". 
The influencer model emphasizes the relationship of the microcelebrity with - and on - the audience, instead of the representation of an incorporeal organisation which was at stake in celebrity endorsement or brand ambassadorship. This influence is highly dependent on the credibility and reliability with which the vlogger presents the products, becoming a cultural, social, and economic capital (Raun, 2018). As a way to gain those perceptions from audiences, social media creators have to be "willing to reveal intimate or emotional material to appeal to viewers" (Marwick, 2015, pp.346-347). Commercial and affective discourses therefore become enmeshed. García-Rapp (2017) describes how beauty vloggers use vlogs ${ }^{1}$ to attract audiences for an affective connection that engages viewers as loyal followers for the videos focused on beauty products. British vlogger Zoella presents herself as equal to her followers, discussing everyday events, presenting makeup tutorials by rejecting a professional persona, and by sharing personal confessions (Jerslev, 2016). This celebrity logic transforms a particular meld of "influence and intimacy into a new source of money and fame" (Berryman \& Kavka, 2017, p.2). Particularly among child-going-on-teens vloggers in Brazil, Marôpo and colleagues (2018) concluded that the monetisation was founded on their use of standardised jargon, gestures of appeal to, or demonstration of affection to followers, and investment in their self-presentation skills, combined with strong social media presence as well as promotion of offline activities. The female vloggers perform playful videos with an 'emergent femininity', producing confessional and intimate discourses marked by revelations of tastes, thoughts, feelings, and experiences, in close proximity to what Jerslev (2016) calls the 'private self'.

The potential for niche marketing is enormous and "the already close relationship between content producers, advertisers, and consumers has become even more intimate" (Van Dijck, 2009, p.47). For marketers, influencer marketing is a way to generate not only awareness about brands/products among target audiences, but also trusted added-value recommendations. Influencers are thought to influence because they are perceived as equal and authentic to the audience, their intimate stories make them seem approachable and trustworthy (followers believe that their recommendations or discouragements are honest); they are close in age to their audience and so are effortlessly capable to create content that fits the audiences' current frame of reference; and they can easily interact with their followers (Uzunoglu \& Kip, 2014; Westenberg, 2016). Andò (2016) demonstrated that adolescents' perception of young female vloggers as being spontaneous, sincere and normal is crucial to their proximity. The connection of these cordinary celebrities' to brands works as symbolic material for vloggers' performances and as a stimulus for interaction with young audiences, providing a common language and also generating social ties and elements to share and recognize.

The process of converting the gathered attention and the obtained intimacy "to financial capital" (Marwick, 2015, p.344) has been rapidly growing. Besides monetizing videos through the YouTube Partner Program, where content creators get a share of the ad revenue placed by YouTube, they can depict products offered by brands and provide discount links for viewers, as well as do special collaborations with sponsoring brands

\footnotetext{
${ }^{1} \mathrm{~A}$ vlog is a video diary in which youtubers present a monologue-like setting displaying themselves in front of the camera and talking about personal issues, everyday life or other topics often from their bedrooms, or more rarely in documentarystyle (Aran, Biel, Gatica-Perez, 2014; Bakioglu, 2016).
} 
(Hou, 2018). Brands are looking for a way to value their products by inserting them in context and in a personal narrative (Hearn \& Schoenhoff, 2016; Khamis et al., 2016). As before with celebrity endorsement, the association between brands and digital creators is not just beneficial for the former but might also be significant for the latter, as this might also contribute to build an online persona; so "the influence of a youtuber's personal brand is demonstrated through the success of brands collaborating with content creators" (Holland, 2017, p.56). YouTubers know they are assessed by brands - or marketing agents - for different metrics: the number of subscribers, views, likes, comments, replies. They understand how YouTube's algorithm works and learn how to make it work for them - and the industry around them - with 'entrepreneurial calculation' (Hou, 2018): using trending words in the titles, for instance. However, it is also known that 'small' digital influencers may have more loyal audiences, where recommendations might be more efficient. This links with the degree of independence of the influencers to choose the brands they recommend and the ways they do it, as well as to be critical in their presentations of products and services: "although beauty vloggers have more agency over their public profile compared to traditional celebrities, they still need to answer to many industrial forces which make their celebrity status possible in the first place" (ibidem). Another aspect is how influencers may be affected by brand scandals and vice-versa (Abidin \& Ots, 2016).

In looking into the commercial content produced by beauty vloggers, $\operatorname{Hou}(2018$, p.9) states there are three main types of video content: 'tutorial, consumer review, and consumption exhibition”. In 'unboxing' as in other categories such as 'hauls', 'new in' or 'first impressions', the "credibility depends on giving honest and precise information about products", but youtubers or bloggers have not tried them yet (ibidem). In this sense, the author points out that vloggers use these formats to test what audiences want to hear more about.

Thus, microcelebrity has become increasingly monetised, professionalised and industrialised, which includes hiring agents for influencers and for digital influencer marketing, as well as the arrangement of industry events and specific training (Costa, 2017). "On YouTube, a beauty vlogger is also positioned at the conjuncture of several industries: a social media platform, commercial cultural intermediaries, and the advertising market" (Hou, 2018, p.7). Microcelebrity success owes to wider "neoliberal notions of individual efficacy and responsibility; and rests on capitalist faith in enterprising, resourceful and self-directed labour" (Khamis et al., 2017, p.10). Influencers have come to symbolize a form of "DIY celebrity entrepreneurialism" (Bennett, 2011), in a free competing economy. This might be especially appealing to young people in search of career paths, especially at times of austerity (Jorge \& Nunes, 2018).

The audience labour is fundamental to the business model of social media and, for YouTube, "the subscriber is the basic currency in this system" (Postigo, 2016, p.344). Audiences are also crucial in maintaining the status of 'YouTube stars' (idem, p.345), which is inherently precarious as they result from their quantification through algorithms. Interaction between content creators and content 'consumers' is structured by the social media possibilities of the platform (Van Dijck, 2013), and that means that youtubers have to strive to constantly keep the audiences working in their favour. 
The aspect of commodification of audiences through celebrity is an important pillar of celebritization (Driessens, 2012, p.649), meaning "a long-term structural development or 'meta-process' (Hepp, 2012; Krotz, 2007)", whereby there is not just an intensification of celebrity logic, but also "societal and cultural changes" related to it. We can extend this point into microcelebrity culture, as in this case vloggers are fundamental in bringing audiences into the social media platform(s), both by engaging them in everyday use and access by watching content, through comments, likes and shares, and by creating an audience that is both a target of commercial messages and data for other agents (Hearn \& Schoenhoff, 2016, p.213).

\section{Methods}

Since "many studies involving children and YouTube have focused on children as subjects rather than authors of content" (McRoberts et al., 2016, p.335), this article discusses the growing commercialism of vlogging content aimed at youth, by analysing a young digital creator's strategies and the audiences' reactions through YouTube comments. While acknowledging the agency of creators as well as users, our questions are thus: how does a young vlogger integrate commercial content in videos while trying to build an authentic and ordinary young (online) persona, and how do audiences negotiate that commercialism? What kind of subjectivity is being put forward, in terms of gender and in relation to the role Portuguese creators occupy in the digital culture?

We analyse the case of @SofiaBBeauty, a successful 17-year-old Portuguese youtuber, vlogging since she was 12. SofiaBBeauty won the Nickelodeon Kids Choice Awards in Portugal in 2017 (Briefing, 2017) and is making a transition from adolescence to adulthood intensively investing in a self-brand and career opportunities anchored in YouTube. Besides YouTube, where she has 236.000 followers, she is also on other social media - Instagram (247.000), Twitter (134.000), Facebook (41.000²) - and in 2017 she started her blog (http://www.sofiabbeauty.com). Here she presents herself: "through my videos you can understand that I love to talk about what I like the most: food (I love food), travelling, makeup, fashion and give my opinion on several subjects" (About Me, 9/2/2018). She shows her family often, especially her older sister, who works on the back-end of the channel.

Sofia Barbosa, the girl behind SofiaBBeauty, is now a semi-professional video producer: she releases two videos per week, endorses products (showing products she receives from brands, presenting discount codes for her followers, doing special collaborations with brands on her videos, or even serving as a model for advertising) and has started her own products (label). She says she doesn't have fixed contracts, just 'partnerships' (Cardoso, 2017).

The corpus for this analysis was purposive: we selected one video per month of 2017 with different forms of brands/products: haul, giveaway, reviews, first impression, favourites, lookbook or outfit of the day, morning routine, make up, travelling, mention to brand in the title. Videos were watched first, then we

\footnotetext{
2 Data from 20th March 2018.
} 
produced extensive summaries (on aspects of narrative, features of construction of Sofia's persona, and commercial aspects), and information on the videos (numbers of views, likes, dislikes, and comments; length) were collected. Picture 1 presents a still of each video. As for users' comments, they were analysed inductively, in terms of the relationship established with SofiaBBeauty and the branded content ${ }^{3}$.

Picture 1: Stills from SofiaBBeauty's videos in the corpus (Jan-Dec 2017)

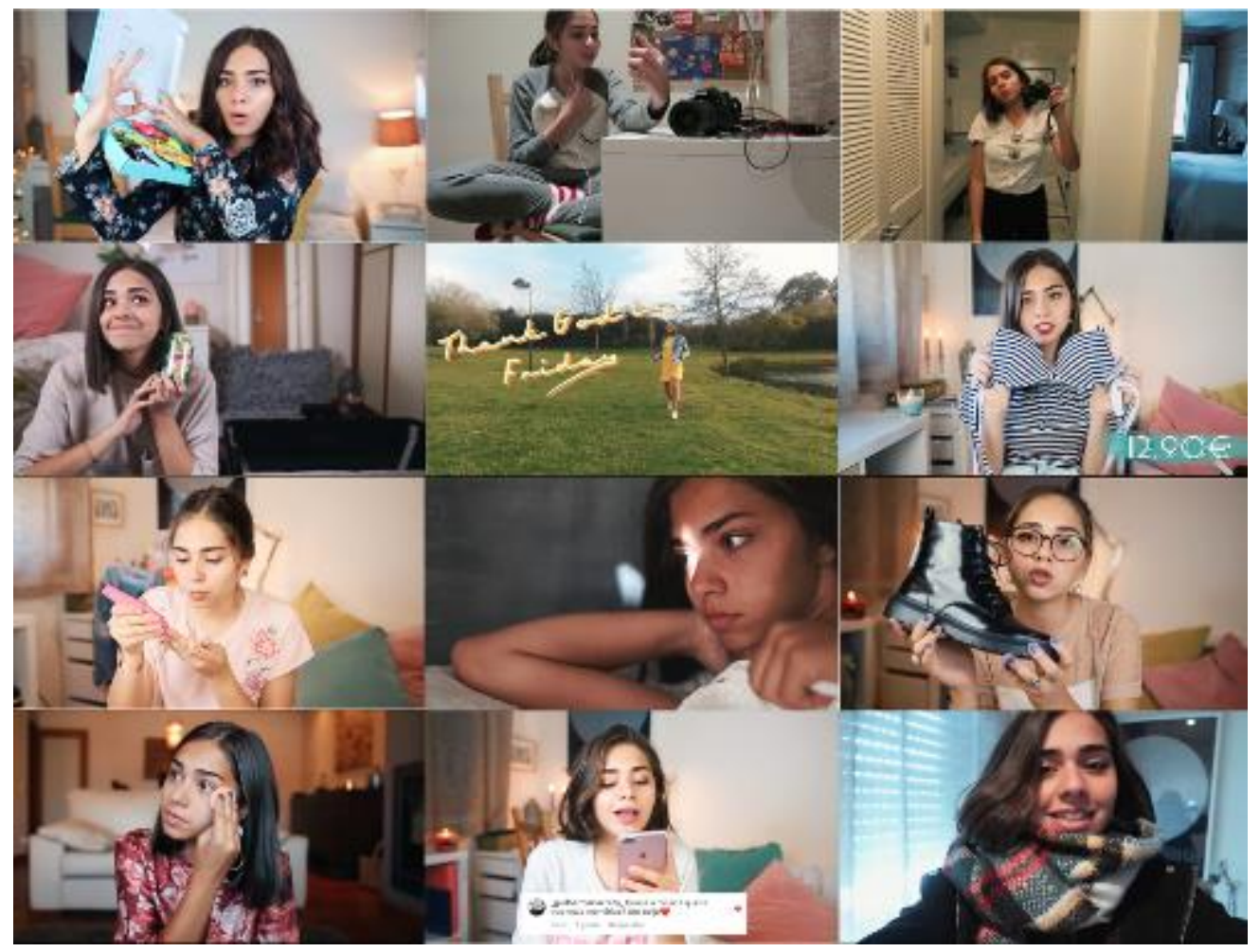

\section{From private self to branded self in the post-feminist era}

As other female vloggers, SofiaBBeauty intercalates explicit infomercial formats (presentation and demonstration of products) on beauty and fashion - such as favourites, haul, first impression, tutorials and lookbook - and more confessional ones - such as vlogs and questions \& answers (Q\&A). In the infomercial formats, she presents and frequently justifies her preferences for specific brands, mainly beauty (skincare and makeup) and fashion (clothes and accessories). Direct product recommendations are rare; Sofia usually

\footnotetext{
${ }^{3}$ We retrieved comments using YouTube Comment Scraper (http://ytcomments.klostermann.ca), exporting them into a spreadsheet, which also included comment threads (replies to comments). We considered all of the comments in the videos (at the date of 29/1/2018), except for one (February), a giveaway with more than 12.000 comments; we selected the first 260 comments, the average of the other 11 videos.
} 
highlights choices in individual terms, as personal preferences that shape her own style. Despite the mix of information and commercialism, the central focus of these videos is usually Sofia's personal experience in trying or using the products. It is as if she is only 'talking' to the followers about her authentic preferences, while spontaneously revealing personal and body characteristics, hesitations on what are the best choices on beauty and also broader interests (food, music, cinema and TV). Sofia is constructing a narrative about herself strongly connected to the brands, frequently relying on a normative femininity.

"I'm trying to get out of my comfort zone, so I bought these sneakers at Zara" (January Favourites: highlighter, La La Land, music, etc!)

"As you know, I have oily skin, but I shouldn't stop moisturizing my skin, it's very important ... (shows Benzacare moisturizer in close-up) ... I like using this moisturizer because it removes the make-up and ends up serving as a primer because it closes your pores...” (Autumn 2017 Make-up)

This personal narrative is reinforced in the confessional formats - vlogs and Q\&A - in which she shares glimpses on several aspects of her life - domestic, family, school - and discloses some 'behind-the-scenes' information. Both formats contribute to value her private authentic self (Jerslev, 2016, p.5240) as a central part of her online persona. In 'Vlog: my 17th birthday', Sofia chronicles her birthday, starting in her bedroom to talk about her expectations; then she comes from school and shows a special table of sweets that her mother and sister prepared for her; she goes out to have dinner with her family and finishes the day in pyjamas without any makeup, again in her bedroom, thanking the followers for the many messages she received on social media. In 'Q\&A: Prom, short hair and travelling', she answers personal questions from the followers (obviously selected by her): "Do you sleep belly down, up, or sideways? How important is travel in your life? If you could ask for three wishes, what would they be? Are you going to have a prom? What is your favourite emoji?". However unpretentious or vulgar, the questions help to construct what Goldsmith (in Berryman \& Kavka, 2017) calls an oblique autobiography. trivial information leaves a lead and helps the reader to construct a narrative about her.

"I'm here with my hot chocolate... By the way [sic], this is Nestlé chocolate powder, I am not a coffee or tea person, so this is how I keep myself warm". (Q\&A: Prom, short hair and travelling)

In documentary as well as talking vlogs, private aspects are 'casually' permeated with brands: e.g. the birthday vlog includes a tutorial when Sofia is putting on makeup for dinner, with products identified in subtitles. The boundaries between the infomercial and confessional formats thus seem to be faded in favour of a strong integration of intimacy and authenticity discourses of consumer culture. With this integration of infomercials in a very spontaneous and casual way, Sofia is constructing a truly branded self (Banet-Weiser, 2011). 
When answering to "Are you thinking of expanding your work beyond YouTube?" in Q\&A, Sofia reveals how her activity as a youtuber is integrated in a larger project of professionalization in the digital sphere encompassing an entrepreneurship of the self (Rose, 1999; Banet-Weiser, 2011). Sofia also announced her intention to work full time as a digital creator, after finishing secondary school (compulsory level) in 2018 (Cardoso, 2017).

"Expanding is very important in our life, in our work. I do not have to be only in YouTube, there is much, much more that I can choose, in this field I think it is important to be not just on YouTube ... Let's think that the owner of YouTube decides to delete it... I have to do something else... There are many new projects that I want to do..." (Q\&A: Prom, short hair and travelling)

The title of all her 2017 videos include the channel's identification at the end - "I SofiaBBeauty"4 -, promoting a distinctive identity and directing more users towards her videos. Her increasingly professionalization, supported by several brands, is also an indicator of an intended commodification process. She had several sponsored trips (travelling to Andorra with a beverage brand, announced in 'What I'm packing for the snow - Sumol Snow Trip'), she won a reference premium for the digital influencers (Nickelodeon Kids Choice Award for Portuguese YouTuber), and she was the official face of Tezenis in its Christmas campaign ${ }^{5}$.

The improvement of the technical quality - good lighting, sound and editing, the well-kept frames, the elegant soundtrack - of her videos is also a sign of her investment towards professionalization. Sofia says that form is as important as content, and that each video takes on average over eight hours to produce (Cardoso, 2017).

So how do the followers relate with SofiaBBeauty's presentation? From a first look on the channel, we could identify mostly positive comments, praising the vlogger and/or the content. On this, affective messages, such as "I love you", "you're beautiful", "you are so cute" are the most usual. Comments that include emotional words of support and motivation for Sofia are also common, while indicating an emotional attachment to her. For example, "You are so good at doing this and you are always getting better", "You are my favourite youtuber and you have a big talent for this!", or "I love your videos and that you keep like this, someone friendly, charismatic and who remains, above all, the kind person that you are".

This complimentary tone of the comments also includes infomercial narratives. For instance, most comments on 'LOOKBOOK No2 2017' - a popular format on YouTube that resembles a combination of a fashion show with a video clip for outfits (one for each day of the week) - praise Sofia's 'work', 'creativity', 'talent' and also the technical quality and aesthetics of the video. Sofia's performance gains centrality, and the outfits become secondary.

\footnotetext{
${ }^{4}$ We don't include this in titles for text economy.

${ }^{5}$ All of this was narrated in detail on her vlogs (the latter was on title of the video 'VLOGMAS Day 4: I am on Tezenis shopping windows!').
} 
I loved it! It is clear that you do things with huge affection, and your so genuine way of being makes your videos unique. I hope you are even more successful, because you deserve it! (R.M.) ${ }^{6}$

Hello Sofia, I really liked the idea of how you interpret the looks and the way you act! One thing I really appreciate about videos is innovative ideas and I think you have achieved this by being natural and yourself! Keep it up! Kisses (J.L.)

Nevertheless, Sofia's apparent distancing from the products/brands is strongly contradicted when looking at the significant amount of questions about the products, when detailed information about them is not available in the video description. The followers want to know the brands, where she bought an item from, and how much it costs. When some user questions directly Sofia about something she has mentioned on the video, another user might be the one answering. Audience's interest in consumer goods may explain why Sofia talks about the products she uses in the videos: she avoids answering questions asked by the audience in the comment section. For instance, in 'Morning Routine: Summer 2017', she says: "if you're wondering, my swimsuit is from Tezenis, my shorts are Zara and my sunglasses are Yourlovelybreeze". Negative or reflexive comments on Sofia's performance or on commercial content are negligible; maybe partially due to possible comment moderation, although it is hard to tell.

\section{Genuine recommendations?}

Sofia recommends mostly clothes and makeup but also food, music/cinema/TV series, interests which are aligned with her presentation on her website. It is not always clear to the audience whether the products/ services were bought by Sofia, given to her by the brands or used by her. In 'First impression of received products', Sofia says: "I'm going to comment on some products for you, whether they were bought by me or offered to me. In this case, they were offered to me. I love to make this kind of videos, because I love to present makeup". Following the format of 'First impression' from other beauty vloggers, she tries the make-up products for the first time on camera, applies them and sees if they work for her, and gives some general review on them, not always praising them, which is part of showing a genuine and 'unfiltered' opinion.

As for clothes, she alludes to buying some items, as a way of showing that she chose and paid for them, and therefore they are something she really likes. Among her 'Favourites' in January, she shows a ZARA scarf that "cost me $€ 19$, it's a bit expensive but totally worth it because it is very warm"; and a denim skirt she says she bought at Pull\&Bear winter sales. This concern for the price of products and looking for bargains can also bring her closer to her young audience, with limited budgets.

\footnotetext{
${ }^{6}$ Because many of the users were real names instead of nicknames, we decided to use initials of names or of nicknames only.
} 
However, this doesn't seem sincere to the audience in 'Haul: bikinis and beachwear', where she shows 13 bikinis and other products of the brand Tezenis, displays the price of each item in the video (see sixth image of Picture 1) and indicates 28 product links in the video description. There is no description of the video being sponsored, since that was not demanded by regulation in the country. However, the fact that solely one brand is in the video indicates that it is sponsored, and some comments point that out:

You might as well say that the video was sponsored by Tezenis... I think it is unlikely someone would buy almost the entire collection of one single brand when there is so much offer on the market. I would also suggest changing the title to 'Haul Tezenis' or something like that. (S.B.)

I love your channel very much but don't call the video a haul if it's clearly a 'presentation' of the brand and if it's sponsored (M.M.)

The video was the most seen among the corpus, and the one with most dislikes (125). One user criticized the brand for being among those that discriminate against girls with different bodies (when they have to buy bikini sets in the same size for top and bottom instead of choosing their own sizes), but criticism towards brands is rare (another rare example is a user - J.S. - saying she really enjoyed the video but 'strongly advising' Sofia to watch The True Cost documentary about the fashion industry and asking her to 'seize her visibility' to share with her audience an opinion on the problems of this industry. Later in 2017, as we said, Sofia would be the chosen face of the Tezenis' pyjamas Christmas campaign, which is shown in several of her December vlogs. Tezenis organised one of her Meets with followers near her hometown, which illustrates the way brand connects the microcelebrity with her audience.

While she does not mention when she is being sponsored, she often says when she is not, partly to affirm her honesty, partly showing that she is not recognised as a top influencer, and maybe to get the brand's attention.

I'm going to show my first shopping on ASOS, it was the first time I ordered clothes online from them... I love going on the website... I am not being sponsored to say this, I wish I was [sic], but I'm not. I really like this shop... You won't find many people on the street with this type of clothing (Autumn Haul: Zara, ASOS and more!)

Although she sometimes shows herself in a position of asking brands for samples or being in the shop already to buy one product, she often attempts to deconstruct the commercial interest behind the brands' offers - and her own interest in receiving them - by portraying the brands' offers as being a result of their affection or kindness for her. This brands' portrayal also overshadows their interest in offering her products, as well as her own material gain, which is seen as disinterested. Recommendations are an extension of her affective social relations. 
Going on to YourLovelyBreeze which is an online store, they sent me some products, they were super sweet, I send them a kiss... (...) When I went there to buy the eyeglasses they gave me..., they were so sweet, in this store downtown, they gave these beautiful sunglasses... (she puts the sunglasses on). These are from the collection handmade [sic] in Portugal, it is really the Portuguese brand that made these glasses... I really liked them. (...) I like them because each model has a different name, from a street in Oporto [her hometown]. Tell me what you think of these eyeglasses... I am not used to them at all. I wanted to record this video for you to see, I like to share these things with you. (Autumn Haul: Zara, ASOS and more)

I'm going to show you the cookies that I found on Instagram (shows the package Kookie Kat)... I was curious, they are organic and vegan... I asked them to send the cookies, people were really sweet... (January Favourites: highlighter, La La Land, music, etc!)

As we mentioned above, many of the followers' comments are about further questions about what is in the video, or asking for other recommendations from Sofia. These comments are often mingled with expressions of affection for Sofia. In 'Lookbook' video, B.DS says: "I Loveeeed it[,] this was awesome!!! Where did you buy the pink coat??? I really want it Congrats"; in 'Vlogmas' I.B. writes 'Hi Sofia! I love your earrings[,] where are they from?".

In anticipating some of the interest in commercial references that she knows the audience might be questioning her about later, Sofia presents in her videos products of brands as something that is part of her daily life. This staging of authenticity also happens in her birthday vlog, where she included a giveaway with 17 different products, from brands that sent her samples, from beauty to music: she thanks each brand and says she 'really likes' some of the brands, the products are "super cute", or the products are from "one of my favourite things, stationery" or music, which "had to be here". In associating this giveaway with her birthday, she is sharing with her followers part of her material gain from being a popular youtuber, thanks to them, while getting the followers to subscribe and comment to be eligible for the prize, thus contributing further to her status.

It is in one of her vlogmas videos that Sofia reflects on the advertising done on YouTube and throughout social media during the Christmas season. She thinks this is a sensitive matter to her audience:

Since we're here I'd like to ask you, I do advertising myself, but lately it seems Instagram, and YouTube itself is full of advertising, seriously, my Instagram feed is only sponsored ads or people advertising. I am speaking against myself because I do it myself, but I'm even afraid of mentioning certain brands or stuff that I really enjoy because you might think I'm being sponsored when I'm not. For example, there is going to be a new [TV] series by Nuno Markl inspired in the 80s and I think this really looks like advertising, if I weren't saying this you would think it is an ad, but it's not. 
If you haven't seen the trailer, go watch it [sic], like, I'm really anxious for it to be out, it's totally my thing... Tell me if you prefer that I say, when I'm advertising, 'ok, this is an ad, this is advertising', would you rather I'd do that? Ok, don't think that when I'm advertising something I don't believe in the product and what I'm saying, don't worry because when I'm advertising something I am being 100\% honest with you, I have no interest in working with brands I don't like or promoting things I don't like... (Vlogmas Let's talk about advertising)

Some comments favour statements of disclosure that she is being paid to advertise, but a few demonstrate a preference for advertisement of products she identifies with, and for her honesty: I.M. says "I think yes you should warn when it's advertising. It doesn't mean that your opinion is not honest, but you're just showing more transparency for potential conflicts of interest" and M.R. writes "If even when you're advertising, you talk about things you're really interested in, it's fine. If it's not advertising, everything's fine anyway". In presenting the issue in these terms, Sofia seems to leave this decision to her followers, not to herself or to regulation. One follower shows some knowledge about what is happening in other countries but seems to distinguish YouTube norms according to countries, which seems to go in contradiction with the tendency of emulation of global youtubers that we will analyse later in this article:

Some time ago, there was a controversy about endorsements [sic] on English Youtube where they are made by law to say they are being paid 'this video was sponsored by...' [sic] or \#ad, on Instagram. I'm not sure but I think this happened with PewDiePie. (...) of course I am speaking of rules in different countries: what is happening there is not necessarily what happens here. I would advise you to seek for more information (m.)

On the one hand, for Sofia, this is a way to reassert her conditions for endorsing products on YouTube videos, and a way to re-legitimate the strategy she has been using, and which consists of her being genuine in her commercial recommendations, while Instagrammers are doing advertising for money. Furthermore, the sponsorship is at the very centre of the authenticity she tries to portray, and at the heart of the connection she attempts to establish with her audience. One comment reads: "sofia [sic] I admire you a lot for being really honest, about everything and also abt[about] this thing of advertising! $\mathrm{i}$ [sic] really like you, keep being the way you are!!!" (J.C.).

On the interview to Público newspaper (Cardoso, 2017), she said she only partners with brands she identifies with, because her motivation is "not money", "I do this because this is how I have fun and meet other people". On the other hand, the fact that she did Vlogmas (one video per day in December) in 2017 is probably due to the fact that YouTube offers different advertising rates according to time of year (Hou, 2018). 


\section{Part of a global community of practice}

Like other Portuguese youtubers (Jorge \& Nunes, 2018), Sofiabbeauty emulates the international YouTube arena, e.g. by using tags in English, often linked to a replica of commercially motivated content and practices. Besides expressions such as 'Haul', 'Lookbook', 'Q\&A' in the titles or descriptions of her videos, 'Morning routine', for instance, sets the scene with a morning ritual, in this case for the middle of the Summer holidays, where skincare plays a role. These video tags also establish protocols and expectations for the audience on formats as they are being established and reinvented.

In this emulation of international, Anglo-Saxon youtubers can be seen especially in the aforementioned 'LOOKBOOK N. 2', where Sofia includes in one video five outfits interpreting literally the themes she claims to see regularly on Instagram as hashtags: "Monday Blues, Taco Tuesday, On Wednesday we wear pink, Throwback Thursday, Thank God is Friday". This strategy is likely to be efficient from the point of view of YouTube algorithm: it increases the chances for a Portuguese youtuber to get more links from Englishspeaking audiences. Sofia's specific strategy for this video also allows her to surpass the discursive logic of Instagram and reclaim herself as a YouTube creator, with more editorial content for commercial recommendations. This seems to have had a good effect on audiences: among the corpus, this was the second most popular video (nearly 137.000 views) and with more comments of appreciation of Sofia as an youtuber or of the video content. Comments include an appraisal of her creativity, good taste and her effort as well as words of encouragement for her to continue.

THIS WAS BEAUTIFUL I L-O-V-E-D it $\square \square$ All the looks, settings, filming were perfect[.] I don't know which one is my favourite look[,] honestly all are great YOU KILLED IT All the work you had was worthh it[.] It is really AMAZING You are among the best YouTubers I follow not just from portugal but international[ly] but of course being from Portugal[,] it’s good to see youtube is moving forward $\square$ Love you Sofz $\square$ (M.D.)

More than that, Sofia also frequently introduces English expressions in speaking (italic below, sic):

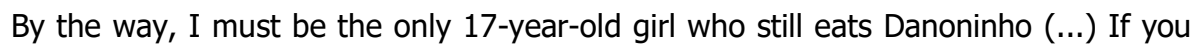
haven't seen the trailer, go watch it (...) Tell me (...) what you think about this matter of advertising, I know it is a very picky subject (Vlogmas Let's talk about advertising)

I am not being sponsored to say this, I wish I was, but I'm not. (Autumn Haul: Zara, ASOS and more!)

Some followers use the same patterns of combining Portuguese and English languages. On the 'Lookbook' video, an example is: "taco tuesday is killing it. i went on modalfa website to see if the blouse is available and it's not, i'm very heartbroken :((“(C.S.). However, one user, J.P. - whose name indicates he is a male user while the vast majority of comments come from users with female names or usernames -, opposes this 
habit from Sofia: "I would only like to ask you to stop using foreign words. It's not even one word every now and then, you might as well speak English only".

As a young Portuguese creator, Sofia is connected with the global, mostly Anglo-Saxon, digital culture, and this connection is stressed and deepened by the presence of brands and products. For instance, in 'Vlogmas', Sofia, while recounting her daily life, includes the ritual of opening up Advent calendars from (mostly beauty) brands, a habit that is not from Portuguese culture, but rather co-opted by lifestyle brands. In the December video, she received 10 comments asking about NYX makeup calendar, which she had stopped showing on her vlogmas by this date, which demonstrates the interest of the audience; she explained later it was not adding to the content she wanted to create.

As a relatively peripheral culture and small market, Portugal is seen as subaltern within the scope of the international YouTube references that Sofia and her mostly Portuguese audience have. In the newspaper interview (Cardoso, 2017), Sofia says she follows and is influenced by other youtubers, including by their recommendations, because, when she started, "Youtube was a 'tiny place', where Sofia only knew [female] foreign youtubers" (Cardoso, 2017). She produces collaborative videos, such as challenges, with reputed youtubers, which help her to mark her own place in a hierarchy of microcelebrity, as one of the pioneers and leading young youtubers in Portugal and in contact with the global youtubers. On the channel's main page, the highlighted video is 'DRAWING CHALLENGE WITH HAILEE STEINFELD' (October 8, 2016), a US young actress, recorded on a trip to London for a film première and press round, probably sponsored by the cinema distributor.

This connection with the global culture is not just happening at the digital sphere but can also be seen in her symbolic investment in travelling, as something she likes, as she says on her website description, and also as something made possible by sponsorships and her success as a youtuber. In 'What I'm packing for the snow - Sumol Snow Trip', Sofia talks about her participation in a sponsored snow camp in Andorra, for students in the secondary senior year on Easter break, while showing the items in her bag, including clothes, makeup and her cameras. Sofia presents herself as inexperienced in skiing, and some of the comments advise her on what to pack and wear, but the video is scheduled to be publish when she is already on the trip, others point out. Other users ask her to make vlogs while on this snow trip; some comment that her makeup on the video is great and they would like a tutorial about it, a few say she should not wear makeup while away, contesting the normativity of makeup. The integration of brand culture in young people's culture starts with the creation of the branded travelling and trickles down to a teen youtuber placing this as a new experience in her life, although the audience does not recognise this as extraordinary, as some of them have had this experience.

In the case of 'California vlogs: we're finally in Los Angeles', however, Sofia seems to be in a superior position, as a result of her success as a youtuber. Through the vlog format, she shares the problems with flights to get to Santa Monica (a remote place from Portugal), and shows her awe of being at the perceived epicentre of cultural hierarchy - both for her acclamation by the mainstream medium of television, and for being at the heart of the production of the American and global popular culture. This might explain the enthusiasm among the comments: the followers who were urged to vote for this award one month before 
congratulate her for winning the Nickelodeon award, say she 'deserves this', and thank her "sharing this adventure with us" (R.B.). Some users also resonate an entrepreneurial discourse, in comments as "Congratulations! Seize every opportunity life gives you, they are unique! \#ontheroadto200k" (C-I); or "UAU!!! have you seen what your YouTube career has given you so far?? $\square \square$ amazing!!!

Branded traveling, initially derived from her visibility, commodifies the audience when she vlogs about it, associates it with yet other products, and ultimately feeds back into further acclaim of the youtuber by the audience. SofiaBBeauty's immersion in brand culture therefore helps to construct her as a cosmopolitan young persona insofar as it permeates her life by offering her new experiences, framed as exclusive, because it is exceptional for a person under 18 to travel alone as often, or have as many opportunities to do something she likes - as opposed to being for work or obligation. Expressed through her language and her experiences, this cosmopolitanism contributes to establish Sofia as an entrepreneur of the self while securing a position as a leading - however young - youtuber from a peripheral country in a global digital community of practice.

\section{Conclusions}

Sofia's self-presentation is interwoven with the presentation of products to her audience: she portrays her commercial recommendations as genuine and sincere, and the followers' comments tend to be supportive of the contents and formats she chooses to depict on her videos. She infuses her self-presentation with affection for the audience as well as for the brands and products around the channel. Sofia adapts discursive strategies that mesh intimacy and commercialism from global youtubers, but audiences appreciate her creativity in presenting content. While audiences appeared to be against sponsored videos not clearly presented as such, they continually ask for Sofia's recommendations, where to find a product she casually shows, and to show more of her daily life. The association with brands also aggrandizes her persona in the eyes of the audience and allows Sofia to reinforce her image as a successful entrepreneur, at the age of (then) 17. Sofia's videos create a post-feminist subject where femininity is articulated with great autonomy, capability, and empowerment for a young person, and where followers are called upon to confirm and expand her success (Berryman \& Kavka, 2017). In her relationship with industries, Sofia stages an excess of autonomy where she wants to appear as being in control of her narrative and her association with brands without a strictly financial motivation. The persona that comes across through SofiaBBeauty channel owes to a neoliberal project, which can be understood within the context of a global cosmopolitanism that is constructed in conjunction with her commercial associations.

On the one hand, we should recognize the opportunities for a young person to be able to express herself and share her creativity with audiences from her country and beyond, especially the most populated Portuguese-speaking country, Brazil. On the other hand, although SofiaBBeauty has more content that is not as commercially framed than that which was purposively chosen for this article, her YouTube channel and social media persona speak of a wider colonisation of youth culture by the commercial sphere, including 
in the cultural consumption. Furthermore, there are particular gender implications as Sofia contributes to further stress the normativity of feminine self-care through fashion and makeup.

This paper has also made evident how the circuits of global culture play out on digital platforms, as Sofia admits she used Anglo-Saxonic youtubers as reference in 2012 and still incorporates many formats and expressions from them, while she has grown to occupy an important position in the Portuguese social media influencers' community. This suggests a contamination at the level of the creators' industry that is crucial to the economic model of YouTube. Moreover, SofiaBBeauty channel speaks for the instrumental role microcelebrities play in engaging young audiences with social media, namely by following, liking and commenting (Van Dijck, 2013), to provide the data that will allow the algorithms to work and to sell them to advertisers (Hearn \& Schoenhoff, 2016), besides engaging them in a wider consumer culture.

This tension between participation and commercialism that can be seen on SofiaBBeauty's channel raises the aspects of regulation of sponsored content within YouTube and beyond, as well as of media literacy, including aspects of critical and consumer literacy. This means a balance between using similar rules regarding sponsorship and endorsement in different countries, and an empowerment of audiences through media education, especially among young people.

\section{References}

Abidin, C. (2015). Communicative <3 intimacies: Influencers and Perceived Interconnectedness. Ada: $A$ Journal of Gender, New Media, and Technology, 8. DOI:10.7264/N3MW2FFG

Abidin, C., \& Ots, M. (2016). Influencers Tell All? Unravelling Authenticity and Credibility in a Brand Scandal. In M. Edström, A. T. Kenyon, \& E-M. Svensson (Eds.), Blurring the Lines: Market-driven and Democracy-driven Freedom of Expression (pp. 153-161). Gothenburg: NORDICOM.

Alexa (n/d) About website views [online]. http://www.alexa.com/top-sites (last access: 12/03/2018).

Andò, R. (2016). The ordinary celebrity: Italian young vloggers and the definition of girlhood. Film, Fashion \& Consumption, 5(1), 123-139.

Aran, O., Biel, J., \& Gatica-Perez, D. (2014). Broadcasting Oneself: Visual Discovery of Vlogging Styles. IEEE Transactions on multimedia, 16(1), 201-215.

Arthus, J., Drakopoulou, S., \& Gandini, A. (2018). Researching YouTube. Convergence, 24(1), 3-15.

Bakioğlu, B. S. (2018). "Exposing convergence: YouTube, fan labour, and anxiety of cultural production in Lonelygirl15". Convergence, 24(2), 184-204.

Banet-Weiser, S. (2011). Branding the post-feminist self: girls' video-production and YouTube. In M. C. Kearney (Ed.), Mediated Girlhoods: new explorations of girls' media culture (pp. 277-294). Peter Lang: New York.

Bärtl, M. (2018). YouTube channels, uploads, and views: A statistical analysis of the past 10 years. Convergence, 24(1), 16-32. 
Bennett, J. (2011). "Architectures of participation: fame, television and web 2.0". In J. Bennett \& N. Strange (Eds.), Television as Digital Media (pp. 332-357). Durham, NC: Duke University Press.

Berryman, R., \& Kavka, M. (2017). "I Guess A Lot of People See Me as a Big Sister or a Friend": the role of intimacy in the celebrification of beauty vloggers. Journal of Gender Studies, 26(3), 307-320.

Briefing (2017). Esta é a Youtuber favorita nos Nickelodeon KCA 2017. 8/3/2017. https://www.briefing.pt/media-br/39301-esta-e-a-youtuber-favorita-nos-nickelodeon-kca2017.html (last access: 20/3/2018).

Burgess, J., \& Green, J. (2009). Youtube: Online video and participatory culture. Cambridge: Polity Press.

Cardoso, M. (2017). Youtuber: a mais recente profissão dos jovens portugueses. Público, 26/7/2017. https://www.publico.pt/2017/08/26/sociedade/noticia/o-youtube-mudou-o-tipo-de-artista-queexiste-1783445 (last access: 15/02/2018)

Costa, S. S. (2017). Os maiores do Youtuga. Expresso, 19/4/2017.http://expresso.sapo.pt/sociedade/201704-19-Os-maiores-do-Youtuga (last access: 20/10/2017).

Cunningham, S., \& Craig, D. (2017). Being 'really real' on YouTube: authenticity, community and brand culture in social media entertainment. Media International Australia, 164(1), 71-81.

Dantas, T., \& Godoy, R. (2016). Youtubers mirins: mera expressão artística ou trabalho infantil?. Pesquisa sobre o uso da internet por crianças e adolescentes no Brasil: TIC Kids online Brasil 2015 (pp. 95104). São Paulo: Comitê Gestor da Internet no Brasil.

Defy Media (2015). Acumen Report Constant http://media5.break.com/campaigns/acumen/Acumen\%20Constant\%20Content ExecSum\%20Booklet Final2.pdf (last access: 10/04/2018)

Driessens, O. (2012). The celebritization of society and culture: Understanding the structural dynamics of celebrity culture. International Journal of Cultural Studies, 16(6), 641-657.

García-Rapp, F. (2017). Popularity markers on YouTube's attention economy: the case of Bubzbeauty. Celebrity Studies, 8(2), 228-245.

Genz, S. (2015). My Job is Me. Feminist Media Studies, 15(4), 545-561.

Hearn, A., \& Schoenhoff, S. (2016). "From Celebrity to Influencer: Tracing the Diffusion of Celebrity Value across the Data Stream". In P. D. Marshall \& S. Redmond (eds.), A Companion to Celebrity (pp. 194-212). Malden, MA and Oxford: Wiley Blackwell.

Holland, M. (2017). How YouTube developed into a Successful Platform for User-Generated Content. In I. Eleá \& L. Mikos (Eds.), Young \& Creative: Digital technologies empowering children in everyday life (pp. 53-64). Gothenburg: NORDICOM/ The International Clearinghouse on Children, Youth \& Media.

Hou, M. (2018). Social media celebrity and the institutionalization of YouTube. Convergence, 1-20. DOI: $10.1177 / 1354856517750368$.

Jerslev, A. (2016). In The Time of the Microcelebrity: Celebrification and the YouTuber Zoella. International Journal of Communication, 10(19), 5233-5251. 
Jorge, A., \& Nunes, T. (2018). WTF: Digital ambassadors for the young generation? In S.-S. Duvall (Org.), Celebrity and Youth. New York: Peter Lang Pub Inc.

Khamis, S., Ang, L., \& Welling, R. (2017). Self-branding, "micro-celebrity" and the rise of Social Media Influencers. Celebrity Studies, 8(2), 191-208.

Khan, M. L. (2017). Social media engagement: What motivates user participation and consumption on YouTube? Computers in Human Behaviour, 66, 236-247.

Lange, P. G. (2014). Kids on YouTube: Technical Identities and Digital Literacies. Walnut Creek, CA: Left Coast Press.

Lovelock, M. (2016). 'Is every YouTuber going to make a coming out video eventually?': YouTube celebrity video bloggers and lesbian and gay identity. Celebrity Studies, 8(1), 87-103.

Marôpo, L., Sampaio, I., \& Pereira, N. (2017). Top Girls on YouTube: Identity, participation, and consumption. In I. Eleá \& L. Mikos (Eds.), Young \& Creative: Digital technologies empowering children in everyday life (pp. 65-87). Gothenburg: NORDICOM/ The International Clearinghouse on Children, Youth \& Media.

Marôpo, L., Sampaio, I., \& Pereira, N. (2018). Meninas no YouTube: participação, celebrização e cultura do consumo. Estudos em Comunicação, 16(1), 175-195.

Marwick, A. (2015). You May Know Me from YouTube. In S. Redmond \& P. D. Marshall (Eds.), A Companion to Celebrity (pp. 333-349). Chichester: Wiley Blackwell.

Marwick, A., \& boyd, d. (2010). I tweet honestly, I tweet passionately: Twitter users, context collapse, and the imagined audience. New Media \& Society, 13(1), 114-133.

McRobbie, A. (2009). The Aftermath of Feminism: Gender, culture and social change. London, Sage.

McRoberts, S., Bonsignore, E., Peyton, T., \& Yarosh, S. (2016). Do It for the Viewers!: Audience Engagement Behaviors of Young YouTubers. IDC '16 Proceedings of the The 15th International Conference on Interaction Design and Children (pp. 334-343).

Piper Jaffray (2016). 32nd semi-annual Taking Stock With Teens research survey - fall 2016. Minneapolis: Piper Jaffray Companies.

Postigo, H. (2016). The socio-technical architecture of digital labor: Converting play into YouTube money. New Media \& Society, 18(2), 332-349.

Rao, L. (2016). YouTube CEO Says There's 'No Timetable' For Profitability. Fortune, 18/10/2016, http://fortune.com/2016/10/18/youtube-profits-ceo-susan-wojcicki/ (last access: 12/2/2018).

Raun, T. (2018). Capitalizing intimacy: New subcultural forms of micro-celebrity strategies and affective labour on YouTube. Convergence, 24(1), 99-113.

Rose, N. (1999). Governing the Soul: The Shaping of the Private Self. London: Free Association Book.

Senft, T. M. (2013). "Microcelebrity and the Branded Self". In J. Hartley, J. Burgess \& A. Bruns (Eds.), A Companion to New Media Dynamics (pp. 346-354). Chichester: Wiley Blackwell.

Statista (n/d). YouTube - Statistics \& Facts. Available at https://www.statista.com/topics/2019/youtube/ (last access: 10/04/2018. 
Stehling, M., Vesnic-Alujevic, L., Jorge, A., \& Marôpo, L. (2018). The co-option of audience data and usergenerated content: The empowerment and exploitation of audiences through algorithms, produsage and crowdsourcing. In R. Das \& B. Ytre-Arne, B. (Orgs.), The Future of Audiences: a foresight analysis of interfaces and engagement (pp. 79-99). London: Palgrave Macmillan.

Tomaz, R. (2017). O que você vai ser quando crescer? Youtubers, Infância e Celebridade. PhD thesis in Communication and Culture. Brasil: Universidade Federal do Rio de Janeiro.

Turner, G. (2010). Ordinary People and the Media: The Demotic Turn. London: Sage Publications.

Uzunoglu, E., \& Kip, S. (2014). Brand communication through digital influencers: Leveraging blogger engagement. International Journal of Information Management, 34, 592-602.

Van Dijck, J. (2013). The Culture of Connectivity: A Critical History of Social Media. Oxford: Oxford University Press.

Van Dijck, J. (2009). Users like you? Theorizing agency in user-generated content. Media, Culture \& Society, $31(1), 41-58$.

Westenberg, W. (2016). The influence of YouTubers on teenagers: a descriptive research about the role YouTubers play in the life of their teenage viewers. Master thesis in Communication Studies, University of Twente.

Winkler, R. (2015). YouTube: 1 Billion Viewers, No Profit. The Wall Street Journal, 25/02/2015. https://www.wsj.com/articles/viewers-dont-add-up-to-profit-for-youtube-1424897967 access: 15/02/2018).

YouTube $(\mathrm{n} / \mathrm{d})$. YouTube Partner Program overview. Available at https://support.google.com/youtube/answer/72851?hl=en (last access 10/04/2018). 